\title{
Drained cyclic capacity of plate anchors in dense sand: Experimental and theoretical observations
}

\author{
S. H. CHOW*, C. D. O’LOUGHLIN*, R. CORTI†, C. GAUDIN* and A. DIAMBRA $\dagger$
}

\begin{abstract}
This paper provides experimental evidence that shows that the drained cyclic capacity of a plate anchor in dry dense sand may be higher than the equivalent monotonic capacity. The experimental data show that when cyclic loading is low relative to the monotonic capacity, increases in the eventual capacity are observed; when the magnitudes of the cyclic loads are closer to the monotonic capacity, no increases in capacity are observed. These responses are explained in the paper using an elastoplastic macro-element model extended with expandable bounding and memory surfaces that address the increase in strength or stiffness caused by changes in soil density and fabric when the anchor is subject to cyclic loading in dense sand.
\end{abstract}

KEYWORDS: anchors; centrifuge modelling; offshore engineering; sands

ICE Publishing: all rights reserved

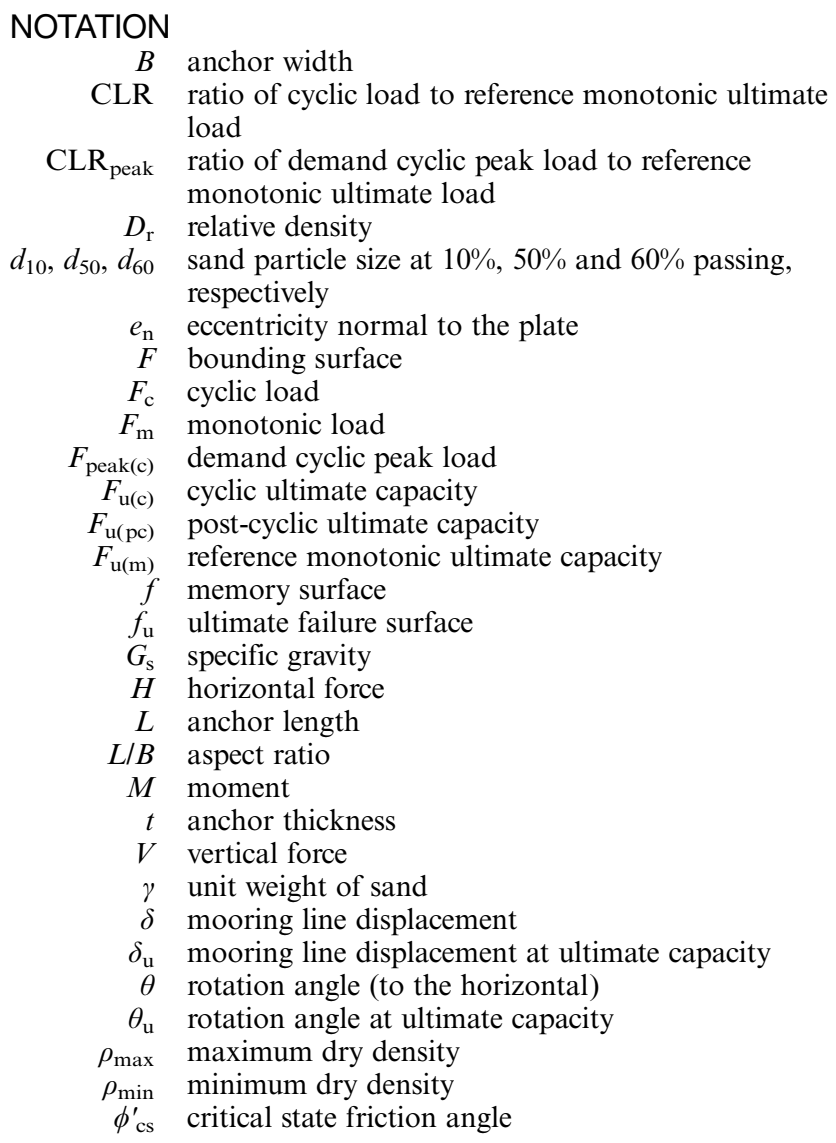

Manuscript received 30 January 2015; first decision 27 February 2015; accepted 10 March 2015.

Published online at www.geotechniqueletters.com on 14 July 2015.

${ }^{*}$ Centre for Offshore Foundation Systems, The University of Western Australia, Perth, Australia

$\dagger$ Department of Civil Engineering, University of Bristol, Bristol, UK

\section{INTRODUCTION}

Plate anchors for offshore applications are subjected to longterm cyclic loading due to the environmental loading acting on the floating facility. Historically, studies that consider the response of soil to long-term cyclic loading have generally been limited to clay as this is the dominant soil type in the deep water environment that plate anchors have been used (e.g. Ponniah \& Finlay, 1988; Andersen, 2009; Wong et al., 2012). However, increasing interest in offshore floating renewable energy devices that are typically located in relatively shallow water with sandy seabeds has led to consideration of the response of plate anchors in sand to long-term cyclic loading.

This centrifuge study investigated the response of a vertically oriented anchor subjected to both monotonic and long-term cyclic loading with a zero degree mudline loading angle in dry dense silica sand. The paper firstly presents experimental data showing drained cyclic capacity that may be equal to or higher than the monotonic capacity, depending on the stress history imposed by the irregular cyclic loading. The possibility of a drained cyclic capacity that is higher than the monotonic capacity is then explained in the second part of the paper using an elasto-plastic macroelement model featuring a memory surface.

\section{EXPERIMENTAL DETAILS}

\section{Model plate anchor and mooring line}

The model plate anchor is a stainless steel rectangular plate of length $(L) 40 \mathrm{~mm}$, breadth $(B) 20 \mathrm{~mm}$ and thickness (t) $2.75 \mathrm{~mm}$, as shown in Fig. 1. The plate, with aspect ratio $L / B=2$ features a triangular-shaped shank with a load attachment point (or padeye) located at an eccentricity normal to the plate $e_{\mathrm{n}}=20 \mathrm{~mm}$ from the centreline of the plate. A two-axis micro-electro-mechanical system (MEMS) accelerometer (Analog Device ADXL278) with a full-scale range of $\pm 70 \mathrm{~g}$ in one axis and $\pm 35 \mathrm{~g}$ in the second (orthogonal) axis was embedded within an epoxy-filled void in the shank to provide continuous anchor rotation measurements during loading. Rotations could be interpreted from the accelerometer measurements as the accelerometer output on each axis varied sinusoidally with rotation angle. Although the plate is likely to experience both changes in embedment depth and rotation during loading, both of which would affect the accelerometer output (due to the varying 


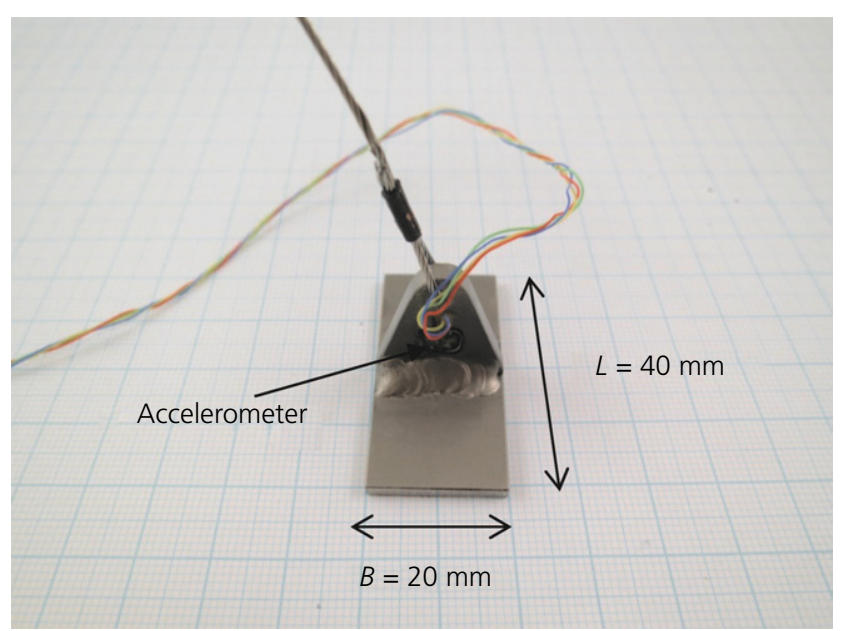

Fig. 1. Model plate anchor instrumented with a two-axis accelerometer

acceleration field in the centrifuge), a considered upper bound embedment change of $1 B$ would be associated with a change in acceleration level of $0 \cdot 6 \mathrm{~g}$, which would result in a maximum error of only $1.3^{\circ}$ in the interpreted rotation measurements. The mooring line was modelled using $1 \mathrm{~mm}$ stainless steel wire.

\section{Centrifuge test setup and procedure}

The centrifuge tests were carried out in a beam centrifuge at an acceleration of $50 \mathrm{~g}$. A dense centrifuge sand sample was prepared by pluviating dry silica sand (with properties as listed in Table 1) into a centrifuge strongbox with internal dimensions of $650 \times 390 \times 325 \mathrm{~mm}$ (length $\times$ width $\times$ depth), to achieve a relative density $D_{\mathrm{r}}=72 \%$. The surface of the sand was then vacuum levelled such that the final sample height was $254 \mathrm{~mm}$.

The experiments were conducted by first installing the anchor (and attached mooring line) vertically at $1 \boldsymbol{g}$ to a padeye embedment depth of $100 \mathrm{~mm}(5 B)$ using a purposemade installation tool on the vertical axis of an electrically driven actuator. The mooring line was then connected to a second actuator positioned such that the mooring line was horizontal on the sample surface (modelling a catenary mooring). The centrifuge was then accelerated to $50 \mathrm{~g}$ to allow for extraction of the installation tool, followed by loading of the anchor. Anchor capacity was measured by a cylindrical in-line load cell $(6 \mathrm{~mm}$ diameter and $25 \mathrm{~mm}$ length) with a capacity of $1 \mathrm{kN}$ connected in series with the mooring line and located above the sample surface. The length of the mooring line between the anchor and the load cell was selected such that the load cell remained at least partially out of the sand during loading. Mooring line displacements were measured by the optical encoder on the vertical axis of the actuator. The experimental arrangement is shown in Fig. 2.

The experimental programme comprised four anchor tests, summarised in Table 2. A reference monotonic test

Table 1. Properties of silica sand

\begin{tabular}{l|l}
\hline Specific gravity, $G_{\mathrm{s}}$ & $2 \cdot 65$ \\
Particle size, $d_{10}, d_{50}, d_{60}: \mathrm{mm}$ & $0 \cdot 10,0 \cdot 19,0 \cdot 22$ \\
Minimum dry density, $\rho_{\min }: \mathrm{kg} / \mathrm{m}^{3}$ & 1461 \\
Maximum dry density, $\rho_{\max }: \mathrm{kg} / \mathrm{m}^{3}$ & 1774 \\
Critical state friction angle, $\phi^{\prime}{ }_{\mathrm{cs}}{ }^{\circ}$ & $30^{\circ}$ (Lehane \& Liu, 2012) \\
\hline
\end{tabular}

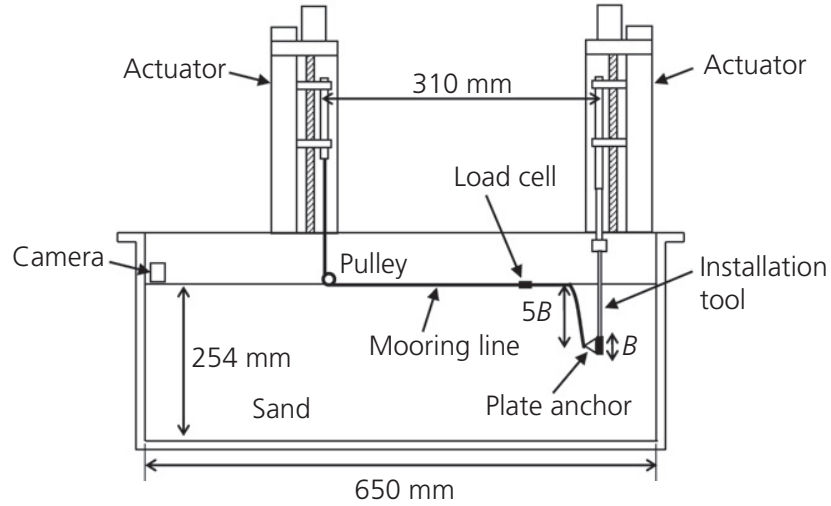

Fig. 2. Experimental arrangement

(called M1) was conducted in which the mooring line was loaded under displacement control at $1 \mathrm{~mm} / \mathrm{s}$. Three cyclic tests (called CLR1, CLR1.25 and CLR1.5) were conducted in which the mooring line was loaded under load control (but at a displacement rate that was limited to the maximum speed of the actuator, $3 \mathrm{~mm} / \mathrm{s}$ ) according to a pre-programmed $1 \mathrm{~h}$ 'storm' of irregular cyclic loads. These cyclic loads were established from wave tank tests on a wave energy converter (Casaubieilh et al., 2014). The three cyclic tests were subjected to the same storm as shown in Fig. 3 (in which $F_{\mathrm{c}}$ is the measured cyclic load), but scaled such that the requested or 'demand' peak cyclic load ratio

$$
\mathrm{CLR}_{\text {peak }}=F_{\text {peak }(\mathrm{c})} / F_{\mathrm{u}(\mathrm{m})}
$$

was equal to $1.00,1.25$ and 1.50 , where $F_{\text {peak(c) }}$ is the demand cyclic peak load and $F_{\mathrm{u}(\mathrm{m})}$ is the monotonic ultimate anchor capacity established from the monotonic loading test. Each cyclic load test involved an initial 'proof-load' stage under displacement control at $1 \mathrm{~mm} / \mathrm{s}$ to $0.7 F_{\mathrm{u}(\mathrm{m})}$, before starting the cyclic loading sequence. A slack mooring was modelled using a nominal $20 \mathrm{~N}$ mooring line load to avoid issues with the load control algorithm trying to achieve $0 \mathrm{~N}$. If the anchor did not fail during cyclic loading (Figs 3 (a) and 3(b)), the anchor was subsequently loaded under displacement control at $1 \mathrm{~mm} / \mathrm{s}$ to measure the post-cyclic loading monotonic anchor capacity.

\section{Centrifuge test results}

The centrifuge test results are summarised in Table 2, which lists (in prototype scale) the measured monotonic, cyclic or post-cyclic ultimate anchor capacity $\left(F_{\mathrm{u}(\mathrm{m})}, F_{\mathrm{u}(\mathrm{c})}\right.$ or $\left.F_{\mathrm{u}(\mathrm{pc})}\right)$ the line displacement at ultimate capacity $\left(\delta_{\mathrm{u}}\right)$ and the rotation angle (to the horizontal) at ultimate capacity $\left(\theta_{\mathrm{u}}\right)$.

Load-displacement curves and the corresponding anchor rotation responses are presented in Fig. 4. Qualitatively, the four load-displacement curves are similar and can be considered in four separate stages.

- During stage 1, the load-displacement response is relatively soft as the mooring line starts to cut through the soil and load develops on the anchor as it starts to 'key' or rotate (by $19^{\circ}$ to $23^{\circ}$ ).

- During stage 2, the load-displacement response is stiffer as more of the load transferred through the mooring line causes rotation of the plate rather than further cutting of the mooring line through the soil. This stage continues to a plate rotation of $34^{\circ}$ to $36^{\circ}$, at which point the anchor capacity is about $65 \%$ of the ultimate monotonic value. 
Table 2. Centrifuge test programme and results (prototype scale)

\begin{tabular}{l|c|c|c|c}
\hline Test & $\begin{array}{c}\text { Peak cyclic load } \\
\text { ratio, CLR }\end{array}$ & $\begin{array}{c}\text { Ultimate anchor capacity, } \\
F_{\mathrm{u}(\mathrm{m})}, F_{\mathrm{u}(\mathrm{c})} \text { or } F_{\mathrm{u}(\mathrm{pc})}: \mathrm{kN}\end{array}$ & $\begin{array}{c}\text { Line displacement at ultimate } \\
\text { capacity, } \delta_{\mathrm{u}}: \mathrm{m}\end{array}$ & $\begin{array}{c}\text { Anchor rotation at ultimate } \\
\text { capacity, } \theta_{\mathrm{u}}: \text { degrees }\end{array}$ \\
\hline M1 & - & $1484 \cdot 0$ & $2 \cdot 99$ & $2 \cdot 80$ \\
CLR1 & $1 \cdot 00$ & $1681 \cdot 1$ & $3 \cdot 12$ & $26 \cdot 24$ \\
CLR1.25 & $1 \cdot 25$ & $1671 \cdot 2$ & $2 \cdot 78$ \\
CLR $1 \cdot 5$ & $1 \cdot 50$ & $1450 \cdot 5$ & $23 \cdot 69$ \\
\hline
\end{tabular}

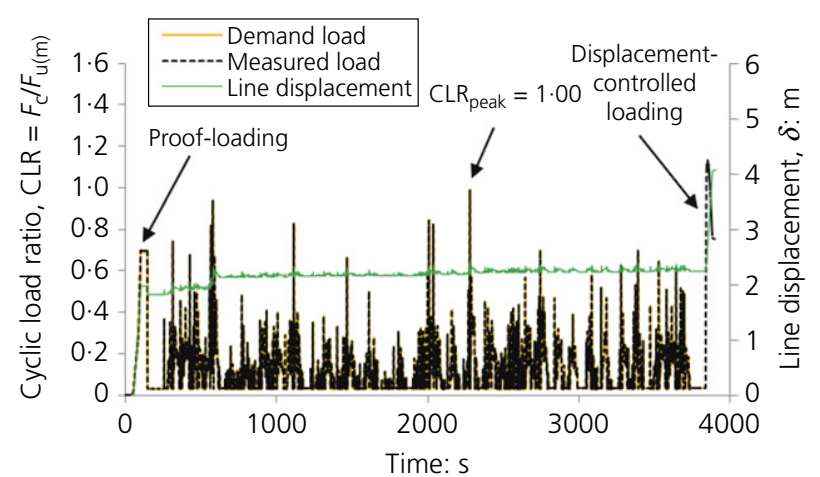

(a)

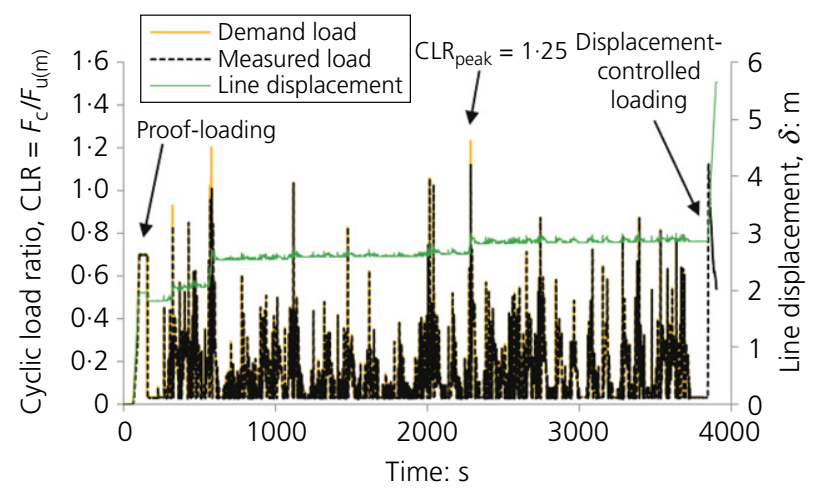

(b)

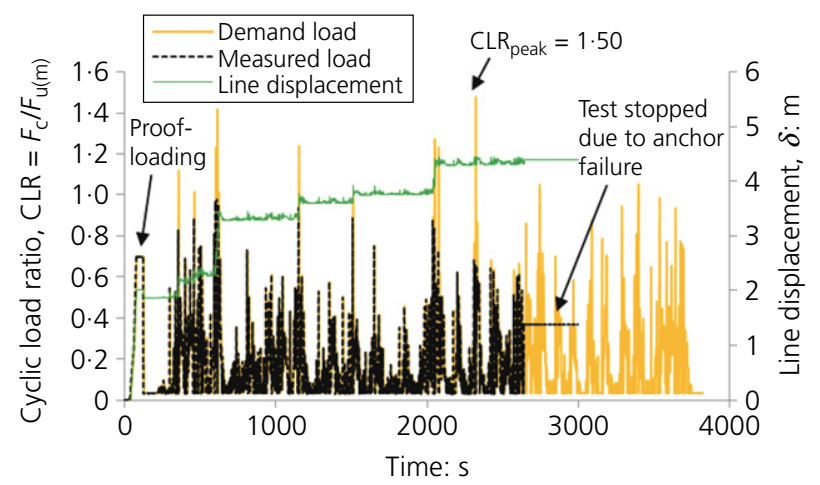

(c)

Fig. 3. Demand and measured cyclic loading sequence for test (a) CLR1, (b) CLR1.25 and (c) CLR1.5

- A third stage is then identifiable during which the rotation reduces. This may be explained by the anchor capacity reaching a threshold at which point it becomes easier for the mooring line to further cut through the sand than for the anchor to continue to rotate. This change in mooring line angle at the padeye causes the anchor to rotate towards the initially vertical orientation, approaching a condition where the mooring line becomes near-normal to the plate and the ultimate capacity is reached at a rotation of $\theta_{\mathrm{u}}=23^{\circ}$ to $28^{\circ}$ (point d in Fig. 4(c)).

- During the fourth and final stage, anchor rotation continues to decrease as the load reduces, eventually reaching a rotation of $13^{\circ}$ to $14^{\circ}$ (point e in Fig. 4(c)) when the test was stopped.

The full sequence of demand and measured loads for each test are shown in Fig. 3 together with the corresponding mooring line displacements. In cyclic tests CLR1.25 and CLR1.5, the measured load was less that the demand load when the cyclic load ratio $\mathrm{CLR}=F_{\mathrm{c}} / F_{\mathrm{u}(\mathrm{m})}$ exceeded 1 (see Figs 3(b) and 3(c)). These points of loading (CLR > 1) tend to coincide with notable increases in the line displacement. Figure 4(a) shows that tests CLR1 and CLR1.25 did not fail during cyclic loading, but at a demand CLR $>0.92$, the cyclic load-displacement response overshot the response from the monotonic test. In both tests the cyclic loading sequence was followed by displacement-controlled loading, as indicated in Figs 3(a) and 3(b), producing identical post-cyclic ultimate loads $F_{\mathrm{u}(\mathrm{pc})}$ that are approximately $13 \%$ higher than the reference monotonic ultimate capacity. Interestingly, the cyclic test with $\mathrm{CLR}_{\text {peak }}=1 \cdot 50$ (test CLR1.5) failed before the monotonic capacity was reached, at a demand CLR $=1 \cdot 43$, producing a loaddisplacement response that was bounded by that measured in the monotonic test extending beyond the ultimate load to a mooring line displacement of $3.48 \mathrm{~m}$, at which point the load-displacement response joins that from the cyclic tests with $\mathrm{CLR}_{\text {peak }}=1 \cdot 00$ and $\mathrm{CLR}_{\text {peak }}=1 \cdot 25$. This experimental evidence, which shows that cyclic loading may affect the magnitude of the anchor capacity, can be captured by a macro-element plasticity model incorporating a newly proposed 'memory surface' as discussed in the following section.

\section{INTERPRETATION FRAMEWORK}

A macro-element modelling approach (Muir Wood, 2011) can be employed to interpret the experimentally observed behaviour of the plate anchor-soil system. In a force-resultant plasticity approach, the allowable combination of loads can be represented by a surface in $H-V-M$ force space where $H, V$ and $M$ are the horizontal force, vertical force and moment acting on the plate anchor, respectively.

A bounding-surface elasto-plastic macro-element model could well describe the observed plate behaviour under monotonic loading conditions. As shown in Fig. 5(a), the current load is represented by a point in $H-V-M$ space and the stiffness is related to the distance of this point to an image load point lying on a bounding surface $(F)$. Following Manzari \& Dafalias (1997) and Gajo \& Muir Wood (1999), the bounding surface represents the peak stress ratio (or current available strength). For a dense soil, the bounding surface is larger than the ultimate failure surface $\left(f_{\mathrm{u}}\right)$ which, however, is asymptotically approached at very large displacements. This type of model would predict the typical force-displacement behaviour for monotonic loading 


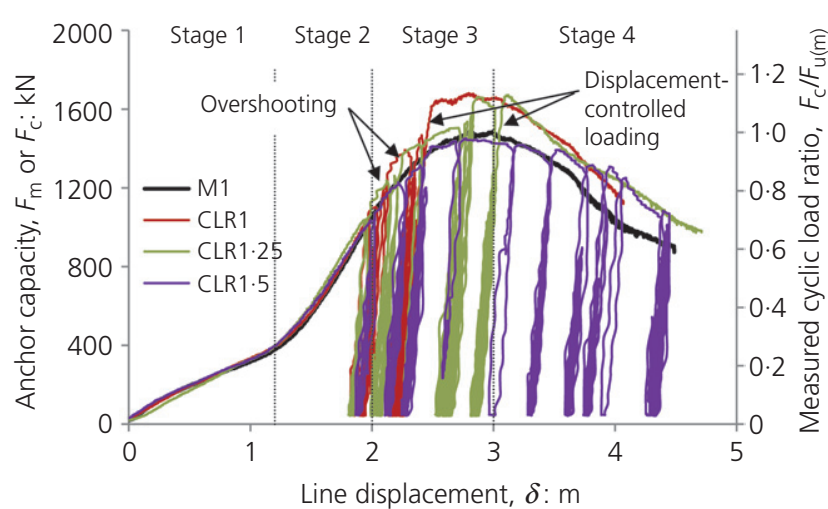

(a)

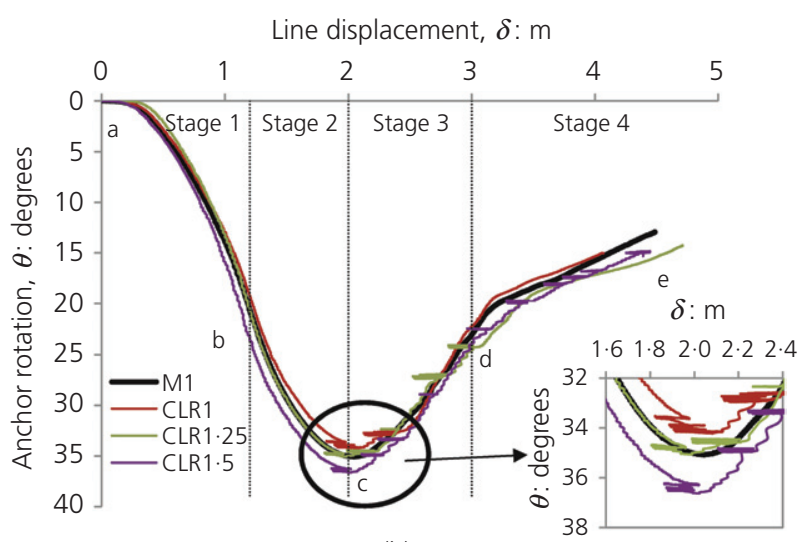

(b)

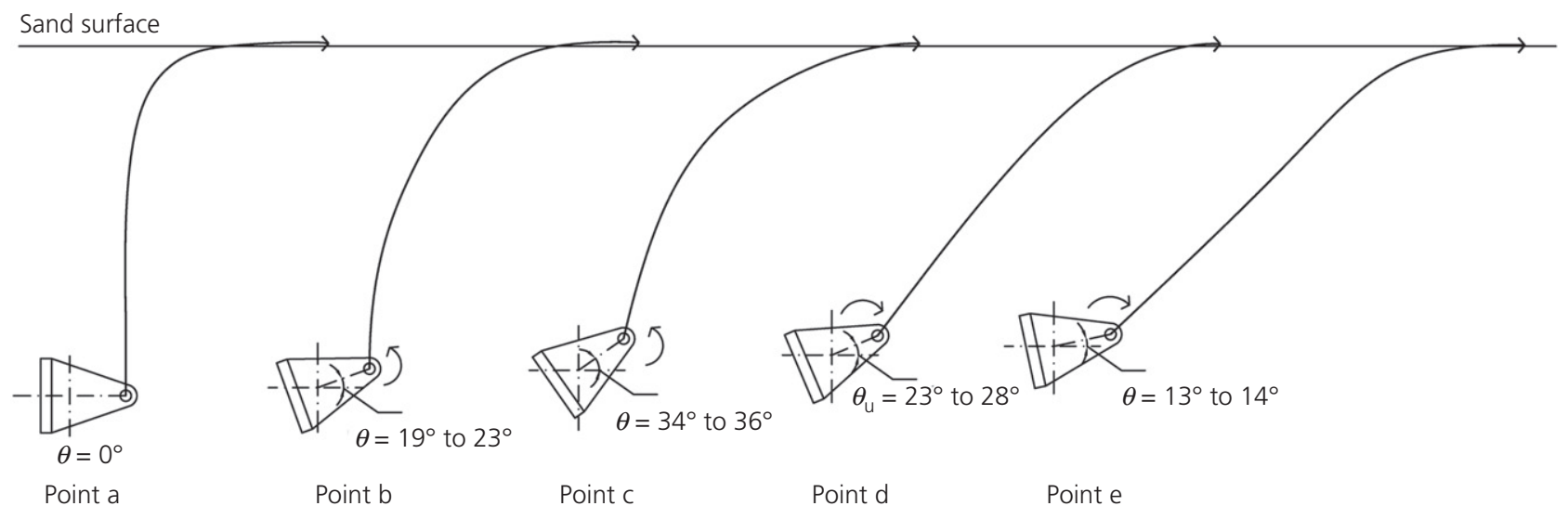

(c)

Fig. 4. Experimental results: (a) load-displacement response; (b) rotation-displacement response; (c) proposed anchor-line behaviour at each stage in the rotation-displacement response

conditions shown in Fig. 5(b), which is similar to the response measured in the monotonic test M1 in Fig. 4(a).

Additional modelling features should be considered to capture the macro-element behaviour under cyclic loading. Wichtmann (2005) showed that soil elements undergoing cyclic loading experience density and soil fabric changes, generally leading to a more stable configuration that increases soil stiffness and decreases the accumulated strain rate. Subsequent monotonic loading applied after the cyclic sequence shows a significant overshooting effect (Wichtmann et al., 2010). These effects are similar to those caused by creep in granular soils observed by Tatsuoka et al. (1997) and can be captured by imposing a progressive hardening (expansion) of the yield surface associated with creep or cyclic loading deformation. Thus, a new memory surface $(f)$, which tracks the already experienced force states and bounds an area of increased stiffness, is introduced in the macro-modelling framework, as shown in Fig. 5(c). Considering that the experimental data indicate constant plate rotation (and thus constant moment $M$ ) during the cyclic loading stage (see the inset within Fig. 4(b)), the new modelling framework is considered along a slice in $H-V-M$ space (at constant $M$ ) such that the representation can be reduced to $H-V$ force space. Cyclic loading applied within the memory surface causes its expansion. The typical framework interpretation for force-displacement behaviour of a system subjected to cyclic loading followed by monotonic loading to failure is also shown in Fig. 5(d). During load path $\mathrm{A}-\mathrm{B}$, the memory surface increases in size as the soil is loaded to unknown conditions. When drained cyclic loading is applied between points $\mathrm{B}$ and $\mathrm{C}$, the current load lies within the memory surface which bounds the high stiffness region. The applied cyclic loading induces changes in both soil density and fabric, which lead to respective increases in the bounding (strength) and memory surfaces. Thus, larger peak strength and an extended zone of high stiffness would be observed during the subsequent monotonic loading to failure, indicated by the load path C-D-E in Figs 5(c) and 5(d). However, densification and fabric effects will be erased at very large deformation when the bounding and memory surface will asymptotically approach the ultimate failure surface $\left(f_{\mathrm{u}}\right)$, point $\mathrm{E}$.

Such a framework can explain the centrifuge test results (Fig. 4(a)). For tests CLR1 and CLR1.25 (with CLR peak $=$ 1.00 and 1.25 , respectively), the continuous application of cyclic loading is expected to cause a progressive expansion in both the bounding and memory surfaces, which results in an increase in strength and overshooting (as indicated in Fig. 4(a)) when a higher peak load is applied during the cyclic sequence or at the final monotonic loading. However, in test CLR1.5 $\left(\mathrm{CLR}_{\text {peak }}=1.50\right)$ the pre-peak stages involved large cyclic loads that regularly pushed the current load state to the boundary of the memory surface, inducing virgin shearing rather than surface hardening associated with densification from the cyclic loading. It follows that the cyclic ultimate resistance is similar to that observed in the monotonic loading case. However, strength increases and overshooting effects are noticeable in the post-peak 


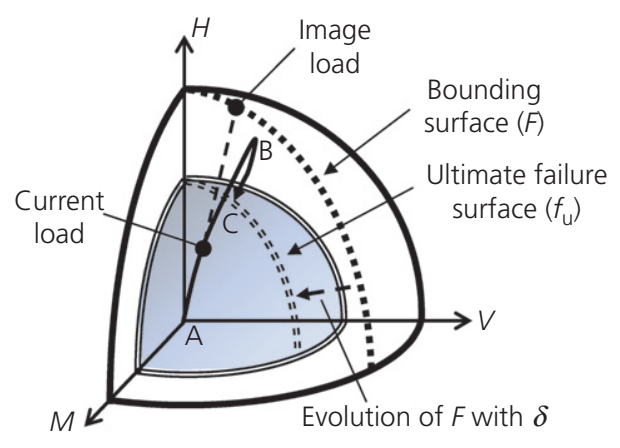

(a)

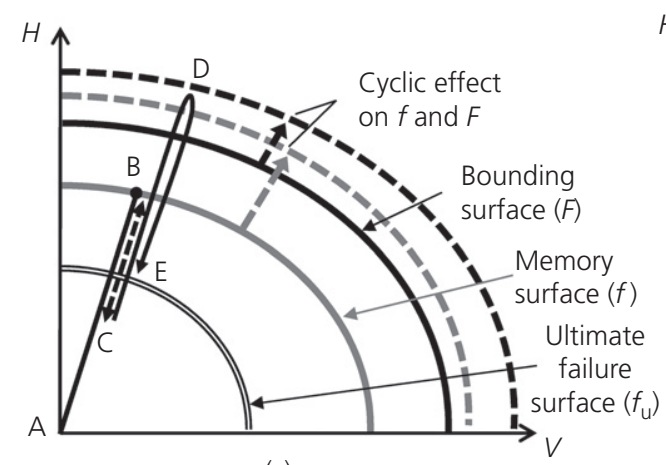

(c)

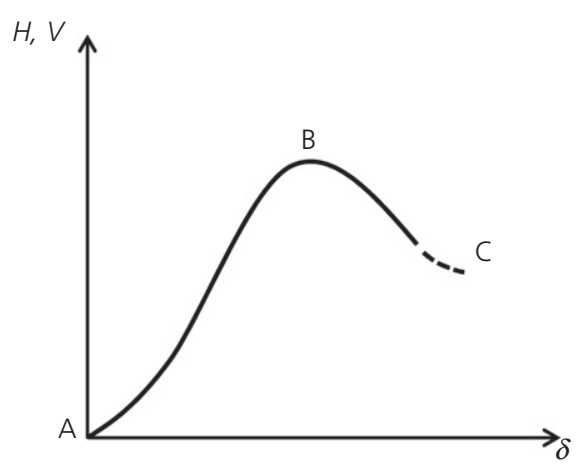

(b)

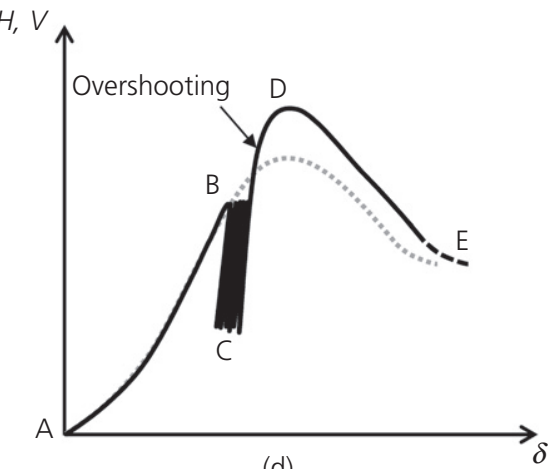

(d)

Fig. 5. Framework representation to describe the behaviour of a plate anchor-soil system: (a) and (b) monotonic loading; (c) and (d) cyclic loading

portion of the force-displacement curve when the memory and bounding surfaces have reached their maximum size and any cyclic loading applied within their boundaries causes hardening when compared to the monotonic case.

\section{CONCLUSIONS}

Drained plate anchor tests in dry dense sand have revealed similar load-displacement and anchor rotation behaviour under both monotonic and cyclic loading. However, the tests showed that anchor capacity is affected by the magnitude of the peak cyclic load, with increases in ultimate capacity that may be about $13 \%$ higher than the monotonic capacity. This 'overshooting effect' may be explained using an elastoplastic macro-element model, which incorporates a proposed memory surface that expands progressively with the bounding surface to capture the increase in stiffness (strength) attributed to sand densification and fabric effects. However, when the loading sequences includes numerous cyclic loads with magnitudes that approach or exceed the monotonic capacity, the current load state is progressively pushed to the boundary of the memory surface soil, such that the soil is primarily subjected to shear rather than densification and no increases in anchor capacity are observed.

The proposed conceptual framework can explain the drained cyclic response of sand, as demonstrated through centrifuge experiments on a plate anchor. The next step in the work reported here is to implement the framework numerically so that it can quantifiably predict the drained cyclic capacity of plate anchors and other foundations in sand. The framework may also be extended to consider undrained responses, which may be more relevant for some applications, such as cyclic loading of suction caissons and monopiles used as foundations for offshore wind turbines.

\section{ACKNOWLEDGEMENTS}

This work forms part of the activities of the Centre for Offshore Foundation Systems (COFS), currently supported as a node of the Australian Research Council Centre of Excellence for Geotechnical Science and Engineering and as a Centre of Excellence by the Lloyd's Register Foundation (LRF). LRF invests in science, engineering and technology for public benefit, worldwide. The third author acknowledges the Worldwide Universities Network (WUN) researchers mobility program, which supported his visit at the COFS at the University of Western Australia.

\section{REFERENCES}

Andersen, K. H. (2009). Bearing capacity under cyclic loading offshore, along the coast, and or land. Can. Geotech. J. 46, No. 5, 513-535.

Casaubieilh, P., Thiebaut, F., Bosma, B. et al. (2014). Performance improvements of mooring systems for wave energy converters. Proc. 1st Renewable Energies Offshore, RENEW 2014, Lisbon, Portugal.

Gajo, A. \& Muir Wood, D. (1999). Severn-Trent sand: a kinematic-hardening constitutive model: the $q-p$ formulation. Géotechnique 49, No. 5, 595-614.

Lehane, B. M. \& Liu, Q. B. (2012). Measurement of shearing characteristics of granular materials at low stress levels in a shear box. Geotech. Geol. Engng 31, No. 1, 329-336.

Manzari, M. T. \& Dafalias, Y. F. (1997). A critical state two-surface plasticity model for sand. Géotechnique 47, No. 2, $255-272$.

Muir Wood, D. (2011). Macroelement modelling. In Mechanical behaviour of soils under environmentally induced cyclic loads (C. Di Prisco \& D. Muir Wood (eds)). New York: Springer, pp. 399-438.

Ponniah, D. A. \& Finlay, T. W. (1988). Cyclic behaviour of plate anchors. Can. Geotech. J. 25, No. 2, 374-381.

Tatsuoka, F., Jardine, R. J., Lo Presti, D., Di Benedetto, H. \& Kodaka, T. (1997). Theme lecture: Characterising the pre-failure deformation properties of geomaterials. Proc. 14th Int. Conf. on 
Soil Mechanics and Foundation Engineering, Hamburg 4, 2129-2164.

Wichtmann, T. (2005). Explicit accumulation model for non-cohesive soils under cyclic loading. PhD thesis, Ruhr University, Bochum, Germany.

Wichtmann, T., Niemunis, A. \& Triantafyllidis, T. (2010). Strain accumulation in sand due to drained cyclic loading: on the effect of monotonic and cyclic preloading (Miner's rule). Soil Dyn. Earthq. Engng 30, No. 8, 736-745.

Wong, P., Gaudin, C., Randolph, M. F., Cassidy, M. J. \& Tian, Y. (2012). Performance of suction embedded plate anchors in permanent mooring applications. Proc. 22nd Int. Offshore and Polar Engineering Conf., Rhodes, 640-645.

\section{WHAT DO YOU THINK?}

To discuss this paper, please email up to 500 words to the editor at journals@ice.org.uk. Your contribution will be forwarded to the author(s) for a reply and, if considered appropriate by the editorial panel, will be published as a discussion. 